persists, it points to the need for attention to the improvement of manufactured smokeless fuels and consequent conservation of high-grade colking coals.

Other papers dealt with ancillary subjectsavailability of British gas coals, purification and marketing of gas and administration. At a time when everything points to the need for conserving coal and promoting efficiency in its use, the series of papers makes a valuable compilation.

H. J. HodsmaN

\section{THE BALANCE OF RESEARCH AND TEACHING AT UNIVERSITIES}

$\mathrm{O}$ NE session at the sixth Congress of the Universities of the Commonwealth, which was held in Oxford during July 19-23, was devoted to what is perhaps the most fundamental of all the problems which face a university: What should be the relation between teaching and research? Should one think of a university primarily as a place where learned men learn more? Or should it be a place where learned men, from their reserves of information, instruct the comparatively ill-informed ? Dr. W.T.S. Stallybrass, vice-chancellor of the University of Oxford, presided at the discussion.

Prof. G. A. Currie, vice-chancellor of the University of Western Australia, introduced the topic by pointing to the very wide difference between the two concepts of a university held by Bruce Truscott, the creator of "Redbrick", and by Ortega Y. Gasset-two authors who have had considerable influence on those who are concerned with university life. Ortega Y. Gasset holds that the inquiring mind has been disastrous, that the constant, restless wish to discover has led the universities from the cultural centre of the community which is their proper place. Bruce Truscott's view is that "an urgent ferment of the mind" is the essence of a university. Unless the teachers are actively engaged in research, their teaching will be barren and unimportant. The spirit of research is the justification of a university. The two theories are diametrically opposed to each other.

None of the representatives assembled at Oxford was prepared to go all the way with Ortega Y. Gasset-though it was noticeable that two Indian representatives spoke most eloquently of the primary obligation of a university being to teach, and emphasized the harm which has been done by an ill-directed urge to publish the results of research of little value. There was general agreement that the question was, in fact, one of balancing two rival claims, each valid in itself, but each in some danger of strangling the other.

However, to say that there is a need to balance the claims of teaching and research is not to say that every university should strike the same balance. The situation, the development and the size of the university are among many factors which must be borne in mind when deciding how much time each teacher should be able to set aside for research. Similarly, the different faculties will give different answers. There was very general agreement among the scientific speakers at Oxford that it is literally impossible for a teacher of any of the scientific subjects to maintain a high standard unless he is given time for private research. Speakers from other faculties were less emphatic. But it was very clear that the need to safeguard the time of the science teachers, who are at present over-worked and overcrowded, is a very pressing need indeed.

It would be desirable to safeguard the time which a teacher should be able to give to his research by limiting the number of hours during which he or she is required to teach. But the curriculum must be so arranged as to give the teacher not merely the requisite number of hours, but also two or three days in each week when he is able to dedicate himself to research without interruption. It is obviously still more desirable to make it possible for the teacher to carry out research elsewhere if it is more convenientwhich can be done only by providing sabbatical years more frequently than any universities can at present afford to do. But sabbatical years are not in them. selves the solution of the problem. The teacher needs to be able to do his research concurrently with his teaching.

The problems of safeguarding the teacher's hours of research, the curriculum which makes it possible for him to carry out research, and sabbatical yearsall these are administrative problems which the governing body of each university must deal with when it has decided how it proposes to balance the claims of teaching and research. The Congress at Oxford did not make any ex cathedra pronounce. ments on this problem. It was obvious that while the representatives assembled in Oxford were very conscious of the existence of the problem, they were equally clear that it is one which must be settled by each individual in each faculty. There is much research now going on which cannot be said to be of any value either to the research worker himself or to the very few students who will read the printed results. But imaginative research, undertaken, not because promotion depends upon it, but because it is a result of the researcher's enthusiasm for his subject, will make him a better teacher-and will be the more likely to be worth-while research. It is the duty of the academic administrators to make sure that they do not so overload the teacher that this type of research is made impossible.

\section{INTERNATIONAL CONGRESS ON MENTAL HEALTH}

$\mathrm{T}$ HE International Congress on Mental Health held in London during August 11-21, was an event of considerable significance for the social sciences and psychiatry, and the repercussions will be felt far afield. It marked a stage in the struggle of these disciplines, on one hand, for acceptance among the family of sciences, and on the other, for recognition in the world of affairs. The undoubted success of the Congress springs from the marriage of these two aims. It is only possible to give here a passing reference to some of the more important aspects of the Congress, to the immense amount of preparatory work, and to the implications for the future.

The Congress comprised three separate international conferences. The first, on child psychiatry, and the second, on medical psychotherapy, were held during August 11-14; the third and main conference, on mental hygiene, during August 16-21. The Congress was organised by the National Association for 
Mental Fiealth, with Dr. J. R. Rees, formerly consulting psychiatrist to the British Army, as president. About two thousand people attended from some fifty countries.

The conferences on child psychiatry and psychotherapy were run on conventional lines. For the first conference the theme chosen was the development of personality in its individual and social aspects, with special emphasis on aggressiveness. Specific topics included aggression in relation to emotional development and in family life, psychiatric problems in education, and the community and the aggressive child.

The subject of guilt formed the theme of the second conference. This was considered under the headings : genesis of guilt, guilt and the dynamics of psychological disorder, and collective guilt. Several of the papers were of exceptional merit, notably those by Dr. John Rickman and Dr. Margaret Mead. The fourth day of this conference was devoted to advances in group therapy. Here the most interesting contribution was perhaps made by Dr. Bion, originator of the 'leaderless group' technique first used in officer selection in the British Army. In the group procedures employed by him, Dr. Bion found it important to elucidate three aspects, first, the group 'mentality' created by the anonymous participation of members; second, the efforts of the members to achieve a full life in the group ; and third, the culture of the group.

The Intermational Conference on Mental Hygiene was the third in a series, the first having been held in Washington in 1930, and the second in Paris in 1937. Under the broad heading of "Mental Health and World Citizenship", five topics were considered : problems of world eitizenship and good group relations, the individual and society, family problems and psychological disturbance, mental health in industry, and problems of planning. The Conference had the active support of Unesco and the World Health Organisation.

In addition to the plenary sessions, there were more than twenty specialist group meetings, sponsored by such professional bodies or organisations as the Maudsley Hospital, the Institute for the Scientific Treatment of Delinquency, the Royal Society of Medicine, the Tavistock Institute of Human Relations and the British Psychological Society.

The preparations for this conference were on altogether novel lines. Indeed, the conference may be said to have begun eighteen months ago when multi-disciplined professional groups were formed all over the world to collect and evaluate available data, or carry out new inquiries, bearing on the conference topics. During the intervening period about five thousand members of the professions concerned worked in discussion groups in twentyseven countries. Their deliberations resulted in some three hundred reports dealing with various aspects of the themes chosen for each day of the conference. About one in ten of the members of these discussion groups attended.

These groups were kept in touch with one another by a printed bulletin issued periodically. Ten such bulletins were circulated, and the contents included not only notes on the work of each of these groups, but also a critical discussion of the aims of the conference. The bulletin will continue to circulate for some time after the Congress, so as to provide an early opportunity for publishing material not to be included in the Congress Proceedings.
The three hundred reports, classified according to the five conference topics, were collated and carefully edited, and the edited material passed on to an International Preparatory Commission for further study.

In my opinion, the work of the International Preparatory Commission was the outstanding point of interest in the Congress as a whole. The primary tasks of the Commission were to examine the reports of the national study groups and to prepare a statement to serve as a basis for consideration at the conference. The Commission consisted of twenty members from ten countries and representing disciplines including psychiatry, sociology, psychology, political science, anthropology and social science. The chairman was Mr. Lawrence K. Frank (director of the Caroline Zachry Institute of Human Development). Dr. Otto Klineberg attended as representative of the Unesco project on "tensions affecting international understanding"; and during the last two days, Dr. Brock Chisholm, director-general of the World Health Organisation, was present as observer.

The statement produced by the International Preparatory Commisssion is a document of great significance, not so much because of any original pronouncements it makes, but because it conveys the agreed views of a group of experts from many countries on issues of great moment to-day, particularly those arising out of the problem of war. The statement includes recommendations addressed to national organisations and United Nations agencies in any way concerned with 'mental health'. It is important to make clear that this term 'mental health' was not used by the Commission in any narrow sense, certainly not in the sense of a state of mind which secures immunity from certification under the Lunacy Laws. It denoted rather a state of social well-being, affecting and affected by every important aspect of the life of the individual and community.

Those who took part in the work of the International Preparatory Commission found it a unique and remarkable experience. Ample opportunity was provided to observe tensions in the making, and there were many such tensions to overcomeinter-national, inter-disciplinary and inter-personal. It is safe to say that, in my view, in this particular group the third type of tension was the most difficult to resolve. In the result, an astonishing degree of group cohesion was achieved and a wide measure of agreement on controversial issues cutting across many disciplines. The major psychological effect on the individual members was the extent of 'group involvement' which many of them experienced.

Overshadowing all other topics in the minds of the members of the Commission was the problem of mental health in relation to world citizenship, or more correctly perhaps, as Dr. Edward Glover put it, the problem of "diseases of sovereign groups". Much thought was devoted to detecting points of intervention in the vicious circle of sovereignty and preparation for war; this is discussed in the statement.

Of special interest was the light thrown on the processes involved in an intimately co-operative intellectual effort, on the technique of approach to complex problems, on the correct division of labour between individual and group in a collective activity of this kind, and above all on the curious distorting effect of unconscious factors on reality thinking, even 
to the extent of blocking the recognition of the most crucial problems of all.

One triumph of the Commission was the final acceptance of the view that what is understood by the term 'mental health' is part of a system of values; it is, in other words, a culturally determined and approved end. It required a tremendous effort to pluck out this view from the mass of anxieties, tensions and resistances which obscured it.

If the Commission made no striking new discoveries, at least it brought to light the fact that multi-disciplined thinking involves more than the mere coming together of diversely educated persons in order to exchange views. Multi-disciplined thinking may operate at many levels. In its most rudimentary form it is simply 'additive', combining the points of view of different disciplines. At a more advanced stage, it requires a new type of concept, which reflects the many-faceted situations of real life. This is one aim of operational research which is essentially a multi-disciplined activity.

The major outcome of the Congress was the formation of a World Federation for Mental Health. This Federation has already been accepted by the World Health Organisation and Unesco as a consultative body on all matters pertaining to mental health in the widest sense. The new organisation will have its roots in the professional groups formed in so many countries to prepare the way for the Congress. These groups will be strongly encouraged to broaden the base of their activities to include all the social sciences as well as psychiatry, and machinery will be devised to link all these groups with the new World Federation. In the way it is hoped to mobilize all the efforts of social scientists, in research and practice, towards the study of the most urgent human problems agitating the contemporary world. JOHN COHEN

\section{OBITUARIES}

\section{Dr. P. R. Lowe, O.B.E.}

Percy Roycroft Lowe, who died on August 18, was born at Stamford, Lincolnshire, on January 3, 1870. He was educated privately and went to Jesus College, Cambridge, where he graduated as a B.A., and afterwards qualified in medicine and surgery at Guy's Hospital, London. He served as house physician and surgeon at two hospitals in the Midlands. In 1899 he volunteered for service in South Africa and was appointed medical officer in charge of Princess Christian's hospital train. It was while he was in South Africa that he became interested in ornithology and began to make a collection. On the termination of hostilities he returned to Great Britain and a short time afterwards was appointed private physician to Sir Frederic Johnston. This was a most fortunate appointment for an ornithologist, as Sir Frederic Johnston spent the winters abroad in his private yacht and during the next six years Lowe visited the West Indies and a number of islands in the Atlantic. On these voyages he took every opportunity to study birds and brought together a collection of some three thousand skins which he later presented to the national collection. Lowe contributed a series of papers on his collections, including a study of the genus Coereba, in which he paid special attention to the variations in colour in that genus.
In the First World War, Lowe served in Lord Dunraven's yacht fitted up as a hospital ship, and afterwards as a captain in the R.A.M.C. in command of Princess Christian's ambulance train. In 1919 he succeeded Mr. Ogilvie-Grant in charge of the bird collection in the British Museum, and retired in 1935.

Lowe was specially interested in the anatomy and osteology of birds, and was an exceptionally careful and painstaking worker. He made a close study of the Charadriiformes, or wading birds, and published several papers on their classification based on osteo. logical characters and colour pattern. $\mathrm{He}$ wrote extensively on the ostriches-both recent and fossil. His studies of the primitive characters of penguins aroused a good deal of criticism, but all will admit that his work on the microscopical structure, arrangement and moult of the feathers of these birds was of outstanding importance. For long there had been much discussion as to whether there were two species of the steamer duck (Tachyeres) but it was left to Lowe to prove, in 1934, that there was a volatile and non-volatile species.

Archæologists are indebted to Lowe for proving that the supposed remains of the pheasants from Roman sites in Great Britain are nothing more than the bones of domestic fowls.

It is no exaggeration to say that in the last fifty years Lowe has done more than anyone to advance the study of the anatomy of birds and their classification.

Although Lowe had always been interested in the preservation of birds, it was not until 1925 that he began to take an active part in the cause. In that year he received a letter from the late Prof. Lönnberg directing attention to the grave decline in the numbers of wildfowl in Sweden and asking his advice and assistance. He took up the matter with characteristic energy and started extensive inquiries in Britain and elsewhere. His conclusions, which were published in pamphlet form, went to show that the decline in numbers was mainly due to increased commercialization, and that unless something was done the numbers of wildfowl were bound to go on decreasing. Through his efforts the British Government was persuaded to hold an International Wildfowl Conference in 1927. A year or two earlier the International Committee for Bird Preservation had been founded, and Lowe became secretary of the British Section and for many years was chairman. His efforts in the cause of bird preservation were greatly appreciated on the Continent, and in 1938 he was elected chairman of the European Section. He was president of the British Ornithologists' Union during 1938-43 and in 1946 was awarded the Salvin-Godman Medal for his outstanding work on the anatomy of birds and his efforts in the cause of protection.

In 1924 he married Harriette Dorothy, widow of Charles Parker of Fairlee and younger daughter of the late E. G. B. Meade-Waldo. He is survived by his widow and one daughter. N. B. KINNEAR

\section{Dr. C. A. Elsberg}

Charles Elsberg, who died at his home in Stamford, Connecticut, on March 18, was one of the most distinguished neurological surgeons of his generation. When he started his career, neurological surgery did not exist as a specialty. While brain surgery was being developed by Harvey Cushing, the surgery of the spinal cord, in which Elsberg was to win international renown, was in its infancy. 